fer, were not in geriatric wards, and had poorer outcomes.

\section{Implications of results}

Policy changes such as the introduction of transitional care units are rarely evaluated, ${ }^{9}$ and programmes for patients who are perceived to have low medical but high care needs have been controversial. ${ }^{10}$ Our participants were frail with both medical and accommodation needs. Nevertheless, our results suggest their care can be provided outside hospital.

We acknowledge the support of Aged Care and Housing (ACH) Group, Michael Szwarcbord, deputy chief executive officer of Flinders Medical Centre, and Brendan Hewitt, director of planning and corporate services, Repatriation General Hospital.

Contributors: See bmj.com

Competing interests: None declared.

Ethical approval: Repatriation General Hospital's research and ethics committee, Flinders Medical Centre's clinical research ethics committee, and Noarlunga Health Services' ethics committee.
1 Ebrahim S. New beginning for care for elderly people? Proposals for intermediate care are reinventing workhouse wards. BMJ intermediate ca

2 British Geriatrics Society. Intermediate care: guidance for commissioners and providers of health and social care. London: British Geriatrics Society, 1998. (Compendium document D4.)

3 Pencheon D. Intermediate care. BMJ 2002;324:1347-8.

4 Shah S, Vanclay F, Cooper B. Predicting discharge status at commencement of stroke rehabilitation. Stroke 1989;20:766-9.

5 Hawthorne G, Richardson J, Osborne R. The assessment of quality of life (AQoL) instrument: a psychometric measure of health-related quality of life. Qual Life Res 1999;8:209-24.

6 Griffiths PD, Edwards ME, Forbes A, Harris RL, Ritchie G. Effectiveness of intermediate care in nursing-led in-patient units. Cochrane Database Syst Rev 2004:(3):CD002214.

7 Kramer AM, Steiner JF, Schlenker RE, Eilertsen TB, Hrincevich CA, Tropea DA, et al. Outcomes and costs after hip fracture and stroke. A comparison of rehabilitation settings. JAMA 1997;277:396-404.

8 Kane RL, Chen Q, Blewett LA, Sangl J. Do rehabilitative nursing homes improve the outcomes of care? J Am Geriatr Soc 1996;44:545-54.

9 Carpenter I, Gladman JRF, Parker SG, Potter J. Clinical and research challenges of intermediate care. Age Ageing 2002;31:97-100.

10 Evans JG, Tallis RC. A new beginning for care for elderly people? BMJ 2001;322:807-8

(Accepted 19 August 2005)

doi $10.1136 /$ bmj.38638.441933.63

\title{
Classification of stillbirth by relevant condition at death (ReCoDe): population based cohort study
}

Jason Gardosi, Sue M Kady, Pat McGeown, Andre Francis, Ann Tonks

\begin{abstract}
Objective To develop and test a new classification system for stillbirths to help improve understanding of the main causes and conditions associated with fetal death.

Design Population based cohort study.

Setting West Midlands region.

Subjects 2625 stillbirths from 1997 to 2003.

Main outcome measures Categories of death according to conventional classification methods and a newly developed system (ReCoDe, relevant condition at death).

Results By the conventional Wigglesworth classification, $66.2 \%$ of the stillbirths (1738 of 2625) were unexplained. The median gestational age of the unexplained group was 237 days, significantly higher than the stillbirths in the other categories (210 days; $\mathrm{P}<0.001$ ). The proportion of stillbirths that were unexplained was high regardless of whether a postmortem examination had been carried out or not $(67 \%$ and $65 \% ; \mathrm{P}=0.3)$. By the ReCoDe classification, the most common condition was fetal growth restriction $(43.0 \%)$, and only $15.2 \%$ of stillbirths remained unexplained. ReCoDe identified $57.7 \%$ of the Wigglesworth unexplained stillbirths as growth restricted. The size of the category for intrapartum asphyxia was reduced from $11.7 \%$ (Wigglesworth) to 3.4\% (ReCoDe).

Conclusion The new ReCoDe classification system reduces the predominance of stillbirths currently categorised as unexplained. Fetal growth restriction is a common antecedent of stillbirth, but its high prevalence is hidden by current classification systems.
\end{abstract}

This finding has profound implications for maternity services, and raises the question whether some hitherto "unexplained" stillbirths may be avoidable.

\section{Introduction}

Stillbirths are the largest contributor to perinatal mortality, but current classification systems consistently report about two thirds of stillbirths as being unexplained. ${ }^{1}$ The preponderance of fetal deaths ending up in a non-specific or unexplained category occurs despite the use of three classification methods: the pathophysiological classification by Wigglesworth, ${ }^{2}$ the fetal and neonatal classification, ${ }^{3}$ and the revised obstetric (Aberdeen) classification. ${ }^{4}$

Any classification system that results in such a high proportion of cases being defined as unexplained would seem not to be fulfilling its purpose, which is to help clinicians to understand what went wrong and to derive learning points for best clinical practice; to assist in counselling bereaved mothers and families about the loss, the underlying reasons, and prospects for the future; and to aid public health specialists and commissioners to prioritise health service resources and strategies for prevention.

We developed a classification system for defining relevant clinical categories for stillbirth and we tested the method on a dataset of stillbirths in the West Midlands over a period of seven years.

This article was posted on bmj.com on 19 October 2005: http://bmj.com/ cgi/doi/38629.587639.7C
Perinatal Institute, Birmingham B6 5RQ Jason Gardosi director Sue M Kady perinatal research fellow

Pat McGeown head of midwifery Andre Francis statistician Ann Tonks data analyst Correspondence to: J Gardosi gardosi@ perinatal.nhs.uk

BMJ 2005;331:1113-7 
Clinical

Epidemiology and

Health Outcome

Unit, Flinders

Medical Centre,

Flinders Drive,

Bedford Park, SA

5042, Australia

David Ben-Tovim

director

Department of

Medicine, Flinders

University, GPO

Box 2100, Adelaide.

SA 5001, Australia

Paddy A Phillips

professor of medicine

Correspondence to:

M Crotty

maria.crotty@

flinders.edu.au

\section{Methods}

The data for our study were derived from rapid report forms submitted to the Perinatal Institute from all maternity units in the West Midlands. We analysed data on all stillbirths occurring in the West Midlands population between 1997 and 2003. Data included the date of delivery, gestational age, maternal characteristics, the baby's sex and birth weight, and pregnancy details to ascertain the cause of death, including results of any postmortem examination. The forms list the primary and sometimes secondary causes, which are used to code the relevant classifications. We obtained the denominators (all stillbirths and live births) from the Office for National Statistics.

\section{Classification}

Our new classification system (box) seeks to identify the relevant condition at the time of death in utero. (See bmj.com for the principles on which the system is based.) The system seeks to establish what went wrong, not necessarily why (as the classification does not have to rely on finding an underlying cause, more than one category can be coded if the information is available). The hierarchy starts from conditions affecting the fetus and moves outwards in simple anatomical groups, which are subdivided into pathophysiological conditions; the primary condition should be the first on the list that is applicable to a case.

Fetal growth restriction is included as the last category in group A (A7): a fetus below the 10th customised centile would be assigned this classification only if none of the other specific fetal conditions were present. Secondary coding can be used to increase descriptiveness while maintaining a hierarchy of groups A to I to reflect clinical relevance.

\section{Birth weight for gestation centile}

We calculated customised centiles along previously described principles, ${ }^{56}$ using the gestation related optimal weight software GROW, version 4.6 (www. gestation.net), which calculates the fetal growth potential by adjusting for the fetus's sex and constitutional characteristics known at the beginning of each pregnancy: maternal height and weight, parity, and ethnic origin. The actual birth weight is then compared with the optimal weight predicted for the corresponding gestation, and a "customised centile" is calculated. The method improves the distinction between constitutional and pathological smallness for gestational age, ${ }^{78}$ allowing customised smallness for gestational age to be used synonymously with fetal growth restriction. For missing data such as maternal height or weight at booking, population averages were used.

The calculation of the centile required an estimation of gestational age at the time of death. As in previous analyses of stillbirth weight, ${ }^{79}$ we deducted two days from the gestational age at delivery of each stillborn fetus. This is taken as the average estimated time interval in the third trimester between fetal death and delivery. ${ }^{10}$

\section{Results}

Overall, 2625 stillbirths and 451197 births occurred during the seven year period between 1997 and 2003, representing an average stillbirth rate of 5.82 per 1000 .
The table lists the causes of death according to Wigglesworth, ${ }^{2}$ which is the classification most commonly used for national statistics. ${ }^{1}$ The largest category, $66.2 \%$, was for unexplained antepartum fetal death, and $11.7 \%$ of deaths were associated with intrapartum causes. An equivalent unexplained category was also the largest by the fetal and neonatal classification $^{3}(66.2 \%)$ and the revised obstetric (Aberdeen) classification $(52.7 \%){ }^{11}$

\section{Classification system according to relevant} condition at death (ReCoDe)

\section{Group A: Fetus}

1. Lethal congenital anomaly

2. Infection

2.1 Chronic

2.2 Acute

3. Non-immune hydrops

4. Isoimmunisation

5. Fetomaternal haemorrhage

6. Twin-twin transfusion

7. Fetal growth restriction*

\section{Group B: Umbilical cord}

1. Prolapse

2. Constricting loop or knot $†$

3. Velamentous insertion

4. Other

\section{Group C: Placenta}

1. Abruptio

2. Praevia

3. Vasa praevia

4. Other "placental insufficiency"

5. Other

\section{Group D: Amniotic fluid}

1. Chorioamnionitis

2. Oligohydramnios $\dagger$

3. Polyhydramnios $\dagger$

4. Other

\section{Group E: Uterus}

1. Rupture

2. Uterine anomalies

3. Other

\section{Group F: Mother}

1. Diabetes

2. Thyroid diseases

3. Essential hypertension

4. Hypertensive diseases in pregnancy

5. Lupus or antiphospholipid syndrome

6. Cholestasis

7. Drug misuse

8. Other

Group G: Intrapartum

1. Asphyxia

2. Birth trauma

\section{Group H: Trauma}

1. External

2. Iatrogenic

\section{Group I: Unclassified}

1. No relevant condition identified

2. No information available

$*<10^{\text {th }}$ customised weight for gestational age centile. $\dagger$ If severe enough to be considered relevant. ¥Histological diagnosis. 
Classification of 2625 stillbirths according to Wigglesworth ${ }^{2}$

\begin{tabular}{llr} 
Code & \multicolumn{1}{c}{ Description } & No $(\%)$ \\
\hline A & Congenital defect or malformation & $389(14.8)$ \\
\hline B & Unexplained antepartum fetal death & $1738(66.2)$ \\
\hline $\mathrm{C}$ & Death from intrapartum asphyxia, anoxia, or trauma & $307(11.7)$ \\
\hline $\mathrm{D}$ & Immaturity & $\mathrm{NA}$ \\
\hline $\mathrm{E}$ & Other (infection, other specific causes, accident) & $170(6.5)$ \\
\hline $\mathrm{F}$ & Unclassifiable or unknown & $21(0.8)$ \\
\hline NA=not applicable.
\end{tabular}

The average (median) gestational age at delivery of the stillbirths denoted as unexplained by Wigglesworth was significantly higher than the gestational age of the stillbirths that fell into the other Wigglesworth categories (237 v 210 days; $\mathrm{P}<0.001$, Mann-Whitney $\mathrm{U}$ ).

A total of 1241 of the 2625 stillbirths (47.3\%) had a postmortem examination. The proportion of stillbirths that were unexplained was high regardless of whether a postmortem examination had been carried out or not $(810$ of $1241(65.3 \%) v 928$ of $1383(67.1 \%)$; $\mathrm{P}=0.3)$.

The figure shows the results using the ReCoDe classification. Only 398 (15.2\%) cases remained unclassified as "no relevant condition identified" (I1). The largest category of stillbirths was A7, fetal growth restriction (43.0\%). Of the 1738 unexplained stillbirths according to Wigglesworth (table), the ReCoDe system identified 1002 (57.7\%) as growth restricted.

Information on classification of a secondary condition was available on $1146(43.7 \%)$ of the rapid report forms (figure). A wide spread of secondary conditions was observed for several of the primary classifications. In particular, a large proportion of congenital anomalies were also growth restricted; among the primary fetal growth restriction group (A7), the most common secondary codes were placental abruption, oligohydramnios, maternal hypertensive disease, and intrapartum asphyxia; and intrapartum asphyxia was often a secondary code for stillbirth associated with abruptio.

Overall, the ReCoDe system showed a smaller proportion of deaths in the intrapartum group than did Wigglesworth (3.4\% $v 11.7 \%)$. As suggested from the secondary coding analysis (figure), this was because many cases of intrapartum asphyxia were assigned other primary conditions under the ReCoDe system. Fetal growth restriction and placental abruptio together accounted for 99 (63\%) of the 156 cases with a secondary coding of intrapartum asphyxia.

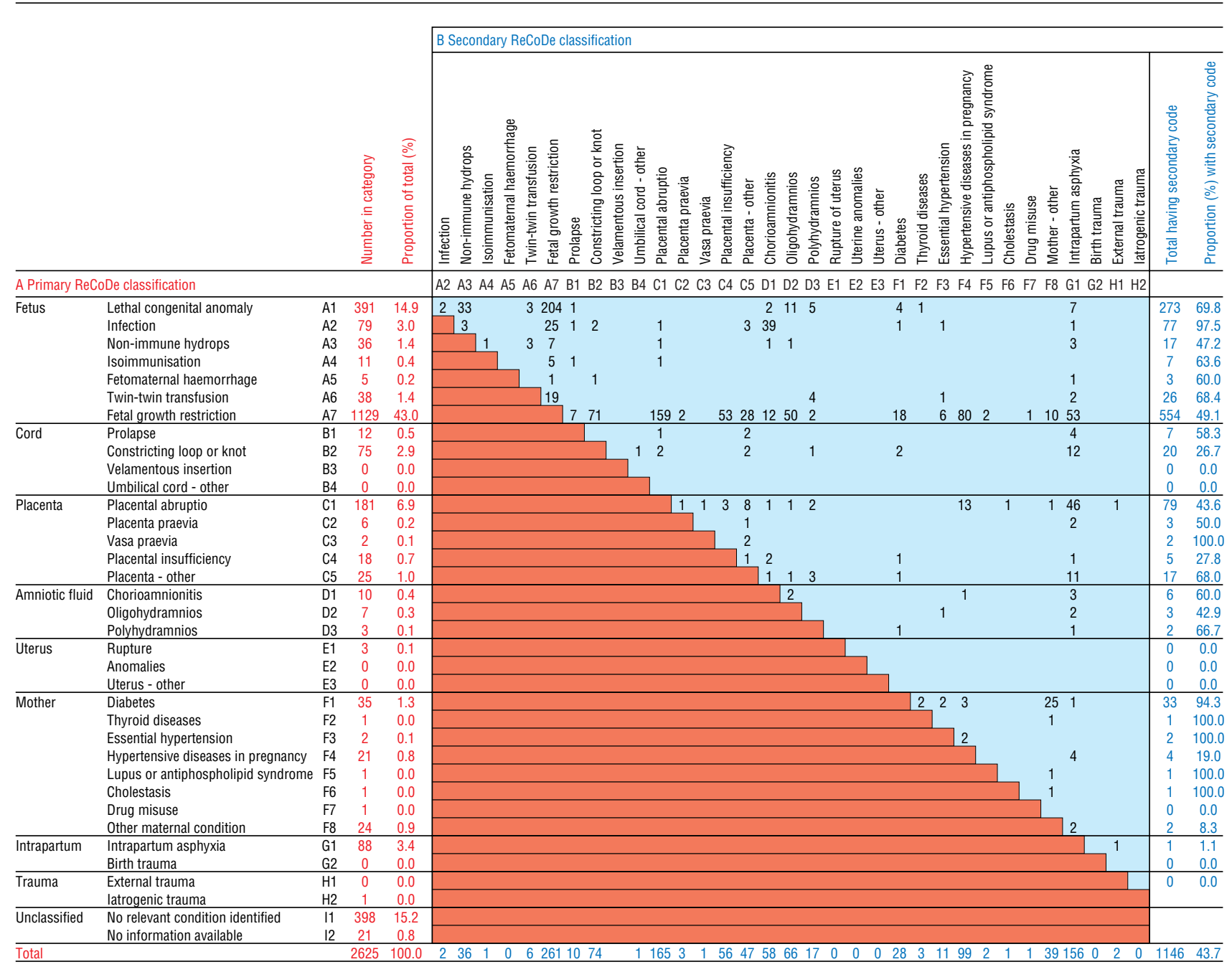

Classification of stillbirths in West Midlands, 1997-2003 using the ReCoDe (relevant condition at death) system 


\section{What is already known on this topic}

Stillbirths are the largest contributor to perinatal mortality

The current method of classifying perinatal deaths results in at least two thirds of stillbirths being classified as unexplained

\section{What this study adds}

A new classification system (ReCoDe) can identify relevant conditions at the time of fetal death in $85 \%$ of cases

Fetal growth restriction is the single largest category of conditions associated with stillbirth and is found in the majority of the cases previously considered unexplained

\section{Discussion}

This analysis of a seven year regional cohort of stillbirths showed that the new ReCoDe (relevant condition at death) classification enabled $85 \%$ of cases of stillbirth to be assigned a relevant condition, leaving only $15 \%$ as unclassified or unexplained. On the same data, the conventional Wigglesworth classification left $66 \%$ of stillbirths unexplained, which is consistent with the reported national rate of unexplained stillbirth. ${ }^{12}$ This raises doubts as to whether classification systems that leave most stillbirths in an unexplained category still have a place in modern perinatal audit.

The single largest condition associated with stillbirth is failure of fetal growth. Such a link does not become evident when perinatal mortality is presented in separate groupings for weight and gestational age. ${ }^{13}{ }^{14}$ Making comparisons within weight categories by controlling for birth weight ${ }^{15}$ can also obscure the fact that many deaths in utero are of fetuses that are smaller than they should be at that gestational age. Nevertheless, even with conventional classification methods, low birth weight emerges as the single largest category. ${ }^{16}$

The extent of the link between stillbirth weight and death becomes most apparent when weight is corrected for gestation. Williams et $\mathrm{al}^{17}$ analysed fetal deaths on population based centile curves in California and showed a strong link between fetal weight for gestation and death. Using measures of smallness for gestation within perinatal death classification systems can result in fewer stillbirths in the unexplained category. ${ }^{19}$

Smallness for gestation has a demonstrable link with fetal death at the population level. However, individually each fetus may be either physiologically or pathologically small, and could be inappropriately classified if only weight for gestation is used. Our classification system therefore uses individually adjustable, customised weight centiles to define which babies had fetal growth restriction. Between a quarter and a third of babies considered small for gestational age $(<10$ th centile) by general population based weight standards are in fact small-normal and have no increased risk of perinatal morbidity or mortality. ${ }^{78}$ A corresponding proportion of babies who should be considered as pathologically small are missed by uncustomised standards, and these have been shown to have an increased risk of perinatal morbidity and mortality. ${ }^{78}$

The use of customised centiles for weight allows us not only to quantify the overall strength of association between stillbirth and pathological smallness but also to identify in each individual case whether the stillbirth occurred after poor fetal growth. Although not strictly a cause of death, fetal growth restriction is an important condition present at the time of fetal death.

The analysis of secondary codes (figure) provides further insight into the conditions leading to stillbirth. Growth restriction is known to have an association with placental abruption and is shown here to have been often present when the abruptio occurred. Similarly, many instances of intrapartum asphyxia resulting in stillbirth were of babies who were already growth restricted.

The category of deaths due to intrapartum asphyxia was much smaller when classified by the ReCoDe system (3.4\%) than by the Wigglesworth classification $(11.7 \%)$. The intrapartum category turns up more often as a secondary classification (figure). Many of these deaths are identified as having another primary condition such as fetal growth failure, highlighting the importance of this condition as an antecedent of intrapartum death

This is consistent with the emerging consensus of a much more important contribution of antepartum, compared with intrapartum, factors on adverse pregnancy outcomes such as cerebral palsy..$^{20}$ The finding would support the notion that good intrapartum care begins earlier in pregnancy: the antepartum course affects the fetus's reserve and ability to withstand stress, and is therefore relevant for determining the appropriate level of surveillance during labour.

Most stillbirths occurred at gestation when the baby would be mature enough not only to survive but to do well, if it could be delivered in good condition This shifts the emphasis on the identification, diagnosis, and management of fetal growth problems. Prospective surveillance can result in the timely delivery of a fetus at risk from an unfavourable intrauterine environment. The main problem facing expectant mothers and clinicians, however, is the lack of recognition within the general maternity population of fetuses with growth problems that are in need of referral for further investigation. In everyday practice, only about a quarter of small for gestational age babies are detected as such antenatally, ${ }^{21}$ and lack of antenatal detection is considered to be the single largest factor associated with substandard care. ${ }^{1}$

The strong link between fetal growth failure and stillbirth has important implications for health policies and preventive strategies, including the need to enhance efforts to improve the antenatal detection of fetal growth restriction.

We thank the West Midlands local coordinators for their consistent efforts in completing rapid report forms on perinatal deaths, and Sarah Badger, Chris Blount, and Donna Drinkall in the Perinatal Institute for coding the data.

Contributors: See bmj.com.

Funding: NHS West Midlands Regional Levies.

Competing interests: None declared.

Ethical approval: Not required. 
1 Maternal and Child Health Consortium. CESDI 8th annual report: Confidential Enquiry of Stillbirths and Deaths in Infancy, London 2001.

Wigglesworth JS. Monitoring perinatal mortality-a pathophysiological approach. Lancet 1980;Sep 27:684-7.

Hey EN, LLoyd DJ, Wigglesworth JS. Classifying perinatal death: fetal and neonatal factors. Br J Obstet Gynaecol 1986;93:1213-23.

Cole SK, Hey EN, Thomson AM. Classifying perinatal death: an obstetric approach. Br J Obstet Gynaecol 1986;93:1204-12.

Gardosi J, Chang A, Kalyan B, Sahota D, Symonds EM. Customised antenatal growth charts. Lancet 1992;339:283-7.

Gardosi J, Mongelli M, Wilcox M, Chang A. An adjustable fetal weight standard. Ultrasound Obstet Gynecol 1995;6:168-74.

7 Clausson B, Gardosi J, Francis A, Cnattingius S. Perinatal outcome in SGA births defined by customised versus population based birthweight standards. Br J Obstet Gynaecol 2001;108:830-4.

8 McCowan L, Harding JE, Stewart AW. Customised birthweight centiles predict SGA pregnancies with perinatal morbidity. Br J Obstet Gynaeco 2005;112:1026-33

Gardosi J, Mul T, Mongelli M, Fagan D. Analysis of birthweight and gestational age in antepartum stillbirths. Br J Obstet Gynaecol 1998;105:524-30.

10 Genest DR, Williams MA, Greene MF. Estimating the time of death in stillborn fetuses: histologic evaluation of fetal organs; an autopsy study of 150 stillborns. Obstet Gynecol 1992;80:575-84.

11 Bound JP. Classification and causes of perinatal mortality. BMJ 1956;ii:1191-6, 1260-5.

12 Confidential Enquiry into Maternal and Child Health. Stillbirth, neonatal and post-neonatal mortality 2000-2003, England, Wales and Northern Ireland. London: RCOG Press, 2005.
13 Chiswick ML. Commentary on current World Health Organisation definitions used in perinatal statistics. I Obstet Gynaecol Br Emp $1986 ; 86: 1236-8$.

14 Scottish programme for clinical effectiveness in reproductive health. Scottish stillbirth and infant death report 1999. Edinburgh: NHS Scotland, Information and Statistics Division, 2000

15 Alessandri L, Stanley FJ, Garner JB, Newnham J, Walters BN. A case control study of unexplained antepartum stillbirths. Br J Obstet Gynaecol 1992;99:711-8.

16 Mcllwaine GM, Howat RCL, Dunn F, Macnaughton MC. The Scottish perinatal mortality survey. BMJ 1979;2:1103-6

17 Williams RL, Creasy RK, Cunningham GC, Hawes WE, Norris FD, Tashiro M. Fetal growth and perinatal viability in California. Obstet Gynecol 1982;59:624-32.

18 Whitfield CR, Smith NC, Cockburn F, Gibson AM. Perinatally related wastage-a proposed classification of primary obstetric factors. Br J Obstet Gynaecol 1986;93:694-703.

19 Huang DY Usher RH, Kramer MS, Yang H, Morin L, Fretts RC. Determinants of unexplained antepartum fetal deaths. Obstet Gynecol 2000;95:215-21.

20 MacLennan A. A template for defining a causal relation between acute intrapartum events and cerebral palsy: international consensus statement. BMJ 1999;16:1054-9.

21 Hepburn M, Rosenberg K. An audit of the detection and management of small-for-gestational age babies. Br J Obstet Gynaecol 1986;93:212-6.

(Accepted 16 September 2005)

doi $10.1136 /$ bmj.38629.587639.7C

\section{Legislation for smoke-free workplaces and health of bar workers in Ireland: before and after study}

Shane Allwright, Gillian Paul, Birgit Greiner, Bernie J Mullally, Lisa Pursell, Alan Kelly, Brendan Bonner, Maureen D’Eath, Bill McConnell, James P McLaughlin, Diarmuid O’Donovan, Eamon O'Kane, Ivan J Perry

\begin{abstract}
Objectives To compare exposure to secondhand smoke and respiratory health in bar staff in the Republic of Ireland and Northern Ireland before and after the introduction of legislation for smoke-free workplaces in the Republic.

Design Comparisons before and after the legislation in intervention and control regions.

Setting Public houses in three areas in the Republic (intervention) and one area in Northern Ireland (control).

Participants 329 bar staff enrolled in baseline survey; $249(76 \%)$ followed up one year later. Of these, 158 were non-smokers both at baseline and follow-up. Main outcome measures Salivary cotinine concentration, self reported exposure to secondhand smoke, and respiratory and sensory irritation symptoms.

Results In bar staff in the Republic who did not themselves smoke, salivary cotinine concentrations dropped by $80 \%$ after the smoke-free law (from median $29.0 \mathrm{nmol} / 1$ (95\% confidence interval 18.2 to $43.2 \mathrm{nmol} / \mathrm{l})$ to $5.1 \mathrm{nmol} / \mathrm{l}(2.8$ to $13.1 \mathrm{nmol} / \mathrm{l})$ in contrast with a $20 \%$ decline in Northern Ireland over the same period (from median $25.3 \mathrm{nmol} / \mathrm{l}$ (10.4 to $59.2 \mathrm{nmol} / \mathrm{l})$ to $20.4 \mathrm{nmol} / \mathrm{l}(13.2$ to $33.8 \mathrm{nmol} / \mathrm{l})$ ). Changes in self reported exposure to secondhand smoke were consistent with the changes in cotinine concentrations. Reporting any respiratory symptom declined significantly in the Republic (down 16.7\%,
\end{abstract} $-26.1 \%$ to $-7.3 \%)$ but not in Northern Ireland $(0 \%$ difference, $-32.7 \%$ to $32.7 \%)$. After adjustment for confounding, respiratory symptoms declined significantly more in the Republic than in Northern Ireland and the decline in cotinine concentration was twice as great.

Conclusion The smoke-free law in the Republic of Ireland protects non-smoking bar workers from exposure to secondhand smoke.

\section{Introduction}

On 29 March 2004, the Republic of Ireland introduced a comprehensive smoke-free law, covering all indoor workplaces. ${ }^{1-3}$ Introduction of this legislation in the Republic but not in neighbouring Northern Ireland was a form of "policy randomisation," creating a natural experiment for identifying effects of the new law.

Cross sectional surveys before and after similar legislation in Finland in 1995 showed a decline in self reported exposure to secondhand smoke. ${ }^{5}$ Bar staff in San Francisco, examined one month either side of the 1998 statewide law in California banning smoking in bars, ${ }^{6}$ showed a rapid improvement in respiratory health.

We examined the impact on bar staff of a national workplace smoke-free law by using laboratory assessment of exposure to secondhand smoke and by

This is the abridged version of an article that was posted on bmi.com on 17 October 2005: http://bmj.com/cgi/doi/10.1136/ bmj.38636.499225.55
Department of Public Health and Primary Care, University of Dublin, Trinity College, Trinity College Centre for Health Sciences, AMNCH, Tallaght, Dublin 24, Republic of Ireland

Shane Allwright senior lecturer in epidemiology Gillian Paul research fellow Alan Kelly senior lecturer in biostatistics

Department of Epidemiology and Public Health, University College

Cork, Brookfield

Health Sciences Complex, Cork, Republic of Ireland

Birgit Greiner senior lecturer in epidemiology and public health Bernie J Mullally research associate Ivan J Perry professor of public health

continued over

BMJ 2005;331:1117-20 